\title{
Social and technological dimensions; and constraint analysis in sugarcane cultivation of Theni district of Tamil Nadu, India
}

\section{Karpagam*}

Central Institute for Cotton Research, Regional Station, Coimbatore - 641003 (Tamil Nadu), India

\section{T. Selvaraj}

M.Sc. ODL Student, Sugarcane Breeding Institute, Coimbatore - 641041 (Tamil Nadu), India

\section{P. Mooventhan}

National Institute of Biotic Stress Management, Raipur - 493225 (Chhattisgarh), India

V. Venkatasubramanian

Sugarcane Breeding Institute, Coimbatore - 641041 (Tamil Nadu), India

*Corresponding author. E-mail: karpsicar@gmail.com

\begin{abstract}
Bridging the yield gap in any crop cultivation should be the prime objective of any research efforts. By following the recommended production-cum-protection technologies, farmers can bridge the yield gap in any crop. As per sugarcane is concerned, the average cane yield in Tamil Nadu is $101 \mathrm{t} / \mathrm{ha}$, which is lower than the potential yield of $203.7 \mathrm{t} /$ ha resulting in yield gap of $50.42 \%$. With this in mind, a study has been initiated to explore the social and technology dimensions and constraints involved in cane cultivation to addressing the issue of yield gap. Six blocks from Theni district under Rajshree Sugars \& Chemicals Ltd were selected as study area. Information collected from sixty sugarcane farmers with semi structured interview schedule. The study revealed that majority $(91.7 \%)$ of the respondents had more than 5 years of experience in sugarcane cultivation. Further, it revealed that the technologies, seed rate $(83.3 \%)$, planting season $(75.00 \%)$, primary tillage with mould board / disc plough (67\%), gap filling, two split application of $\mathrm{N}$ and $\mathrm{K}(58.3 \%)$ and Organic fertilizer application $(58.3 \%)$, stubble shaving, off baring $(50.0 \%)$ had adoption rate of more than 50 percentage. Major constraints faced by cent per cent of the respondents were; non availability of labour and high labour cost, prolonged drought and water scarcity, low procuring cost per by sugar factory, yield reduction due to continuous cultivation of sugarcane. The novelty and importance of the study is that it mainly analysis all the sugarcane production and protection technologies from seed rate to harvest in three point continuum viz., fully adopted, partially adopted and not adopted.
\end{abstract}

Keywords: Constraints, Full adoption and No adoption, Partial adoption, Social and technological dimensions, Sugarcane production system

\section{Article Info}

DOI:10.31018/jans.v11i2.2102

Received: May 6, 2019

Revised: June 4, 2019

Accepted: June 10, 2019$$
\text { - }
$$

\section{How to Cite}

Karpagam, C. et al. (2019). Social and technological dimensions; and constraint analysis in sugarcane cultivation of Theni District of Tamil Nadu, India. Journal of Applied and Natural Science, 11(2): 581- 586 https://doi.org/10.31018/ jans.v11i2.2102

\section{INTRODUCTION}

Being a cash crop, sugarcane plays a vital role in agricultural growth rate. India ranks second in terms of area and production, next to Brazil. Sugarcane was cultivated in little more than 50 lakh hectares and the production has touched a new record of 3,610 lakh tonnes. Although more than $40 \%$ (more than 20 lakh hectares) of the cane area in the country is in Uttar Pradesh, Tamil Nadu ranks first in productivity of sugarcane. Though the area under sugarcane in Tamil Nadu varied widely from 2.3 lakh hectares to 3.9 lakh hectares over the years in the new millennium (2000-01 to 2011-12), the productivity has almost been stabilized at around 105 tones/ha during the same period (Ramasubramanian and Karpagam (2014) and
Karpagam et al., 2016). The average cane yield in Tamil Nadu is $101 \mathrm{t} / \mathrm{ha}$, which is lower than the potential yield of 203.7 t/ha resulting in yield gap of $50.42 \%$. Thus, wide gap exists between the actual yield against the potential yield. Bridging the yield gap should be the prime objective of the research efforts. By following the recommended productioncum-protection technologies, farmers can bridge the yield gap. Therefore, exploring the existing social and technological dimensions and addressing constraints involved in cane cultivation will pave way towards sustainable sugarcane cultivation. With this in mind a study has been initiated with the objectives to study the socio and technological dimensions of sugarcane farmers and to study the constraints in sugarcane cultivation in Theni district of Tamil Nadu. 


\section{MATERIALS AND METHODS}

Based on the predominance in sugarcane cultivation, Theni district was selected for the study. From Theni district; six blocks viz., Cumbam, Chinamanur, Bodinayakanur, Theni, Andipatti and Periyakulam were selected. These blocks are served by the Rajshree Sugars \& Chemicals Ltd. From each block ten respondents were selected; thus 60 respondents constituted the sample. The value of the study largely depended upon the different variables taken into consideration for the study. Five socio economic variables viz., Age, Educational status, Farm size, Farming experience and Risk orientation were selected to study the social dimensions exits in the study area and to study about the technological dimensions; different production and protection technologies were selected. Further, different constraints involved in the cane cultivation were also studied. To collect the information, a comprehensive semi-structured interview schedule was constructed. Utmost care was taken to ensure that the items were clear and unambiguous. With the semi structured interview schedule, the direct field level personal interview was undertaken in the study area with sixty cane growers.

\section{RESULTS AND DISCUSSION}

Social dimension gives a clear-cut picture about the cane farmers' background and their characteristics. The Technological dimension pave the way to understand the technologies which reached the farmers and the technologies has to be transferred. Hence, these two dimensions give holistic view about the cane cultivation in the particular area. Further, constraint analysis revealed the major obstacles faced by cane farmers while continuing the sugarcane cultivation and it also gives clear picture about why the farmers are discontinuing the cane cultivation.

Social dimension: It could be observed from Table 1 that more than fifty-five per cent of the respondents were in $35-50$ age group. Youngster (below 35 years) engaged in sugarcane farming were less per cent $(16.7 \%)$. It may be due to the general trend that in recent years the youth are not undertaking farming and they are more interested in other activities like business and services. Mooventhan et al., (2015) reported that very meager percent (15.67) of the dairy farmers in Northern hill zone of Chhattisgarh were of the age up to 35 years.

Further, Selvam (2014) while studying the technology mapping for sugarcane technologies in Dharmapuri district reported that more than 50 per cent of the respondents were found to be in between $35-50$ age group. The educational status analysis revealed that $16.7 \%, 30.0 \%, 33.3 \%$ of the respondents were illiterate, primary and middle school level of education, respectively. Very meager per cent of the respondents educated beyond the middle school. The results are in line with the findings of Karpagam (2000 and 2009). As per the

Table 1. Social dimensions of sugarcane farmers in the study area $(n=60)$.

\begin{tabular}{|c|c|c|c|c|}
\hline S.No. & Category & Frequency & Percentage & Rank \\
\hline \multicolumn{5}{|c|}{ A. Age } \\
\hline 1. & $<20$ & 4 & 6.7 & IV \\
\hline 2. & $21-35$ & 6 & 10.0 & III \\
\hline 3. & $35-50$ & 35 & 58.3 & I \\
\hline 4. & $>50$ & 15 & 25.0 & II \\
\hline \multicolumn{5}{|c|}{ B. Educational Status } \\
\hline 1. & Table & 10 & 16.7 & III \\
\hline 2. & Primary School & 18 & 30.0 & II \\
\hline 3. & Middle School & 20 & 33.3 & I \\
\hline 4. & High School & 5 & 8.3 & IV \\
\hline 5. & Higher Secondary & 5 & 8.4 & IV \\
\hline 6. & Collegiate & 2 & 3.3 & V \\
\hline \multicolumn{5}{|c|}{ C. Farm Size } \\
\hline 1. & Small farmers ( $<2.5$ acres) & 25 & 41.7 & I \\
\hline 2. & Marginal farmer (2.5 - 5 acres) & 25 & 41.7 & I \\
\hline 3. & Big farmers ( $>5$ acres) & 19 & 16.6 & II \\
\hline \multicolumn{5}{|c|}{ D. Farming experience } \\
\hline 1. & Less than one year & 0 & 0 & IV \\
\hline 2. & 1-5 Years & 5 & 8.3 & III \\
\hline 3. & 5-10 Years & 25 & 41.7 & II \\
\hline 4. & More than 10 years & 30 & 50.0 & I \\
\hline \multicolumn{5}{|c|}{ E. Risk orientation } \\
\hline 1. & Low & 10 & 16.6 & II \\
\hline 2. & Medium & 25 & 41.7 & 1 \\
\hline 3 & High & 25 & 41.7 & I \\
\hline
\end{tabular}


Table. 2. Sugarcane Production and protection technological dimensions in Theni district of Tamil Nadu state $(n=60)$.

\begin{tabular}{|c|c|c|c|c|c|c|}
\hline \multirow{2}{*}{ Production technologies } & \multicolumn{2}{|c|}{ Fully adopted } & \multicolumn{2}{|c|}{ Partial adopted } & \multicolumn{2}{|c|}{ Not adopted } \\
\hline & No & $\%$ & No & $\%$ & No & $\%$ \\
\hline Planting season & 45 & 75 & 10 & 16.7 & 5 & 8.3 \\
\hline Primary tillage with mould board / disc plough & 40 & 67 & 10 & 16.7 & 10 & 16.3 \\
\hline Secondary tillage & 20 & 33.3 & 25 & 41.7 & 15 & 25 \\
\hline $\begin{array}{l}\text { Cultivation of green manure crop - Daincha / Sun } \\
\text { hemp }\end{array}$ & 0 & 0 & 0 & 0 & 60 & 100 \\
\hline FYM application & 35 & 58.3 & 20 & 33.3 & 5 & 8.4 \\
\hline Seed rate & 50 & 83.3 & 10 & 16.7 & 0 & 0 \\
\hline Micro nutrient application & 45 & 75 & 10 & 16.7 & 5 & 8.3 \\
\hline Wider spacing with dual row planting & 5 & 8.3 & 5 & 8.3 & 50 & 83.4 \\
\hline Bud chip settlings used / acre & 0 & 0 & 0 & 0 & 60 & 100 \\
\hline Intercrop & 20 & 33.3 & 15 & 25 & 25 & 41.7 \\
\hline Gap filling & 35 & 58.3 & 15 & 25 & 10 & 16.7 \\
\hline Basal dose of ' $P$ ' Fertilizer & 25 & 41.6 & 25 & 41.6 & 10 & 16.8 \\
\hline Two split application of $\mathrm{N}$ and $\mathrm{K}$ & 35 & 58.3 & 20 & 33.4 & 5 & 8.3 \\
\hline Organic fertilizer application & 35 & 58.3 & 15 & 25 & 10 & 16.7 \\
\hline Irrigation schedule stage wise & 20 & 33.4 & 40 & 67 & 0 & 0 \\
\hline Earthing up & 20 & 33.4 & 30 & 50 & 10 & 16.7 \\
\hline Detrashing & 20 & 33.4 & 25 & 41.3 & 15 & 25 \\
\hline Propping & 10 & 16.6 & 15 & 25 & 35 & 58.4 \\
\hline Trash mulching & 25 & 41.6 & 20 & 33.4 & 15 & 25 \\
\hline Removal of water shoots & 0 & 0 & 0 & 0 & 60 & 100 \\
\hline Drip irrigation & 15 & 25 & 15 & 25 & 30 & 50 \\
\hline Mechanical harvester & 0 & 0 & 10 & 16.7 & 50 & 83.3 \\
\hline Stubble shaving & 30 & 50 & 20 & 33.4 & 10 & 16.6 \\
\hline Off baring & 30 & 50 & 15 & 25 & 15 & 25 \\
\hline
\end{tabular}

farm size is concern, it is quite clear from the findings that majority of the farmers $(83.4 \%)$ in the study area are small and marginal farmers. Very meager percent $(16.6 \%)$ of the respondents comes under big farmers' category. The reason may be that even though the study area is predominantly agriculture dominated area, but the economical status is not on bar with the other developed districts in Tamil Nadu.

Further, due to bifurcation of land over the different generations, the farm size gets fragmented and resulted in more number of small and marginal farm size. And the land reforms act in the state also one of the reason for the small holdings. The similar finding was reported by Mooventhan et al. (2015) as very meager percent (8.67) of the dairy farmers in Northern hill zone of Chhattisgarh were comes under big farmer category. Kumaran et al. (2018) reported that majority of scientific farms in West Bengal $(91.11 \%)$, Kerala $(50 \%)$ and traditional farmers in west Bengal (52.30\%) and Kerala
$(67.90 \%)$ were small farms with less than 2 ha. The reason they reported that the land reforms taken place in these states. As per the farming experience is concern; more than ninety per cent $(91.7 \%)$ of the respondents had more than 5 years of experience in sugarcane cultivation and very meager per cent $(8.3 \%)$ of the respondents had less than 5 years of experience in sugarcane cultivation. Sugarcane is the long duration crop and has several ratoons as well. Sugar factories in Tamil Nadu holding the registered farmers for longer period and the factories assured the farmers for all cultural practices from seed sowing to harvest and the assured income from the sugar factories also one of the reasons for farmers to have longer period of experience in sugarcane cultivation.

Similar findings were reported by Sunitha (1998) while studying the knowledge and adoption of ecofriendly farm Technologies in Paddy and Balasubramaniam (2005) while studying the develop- 


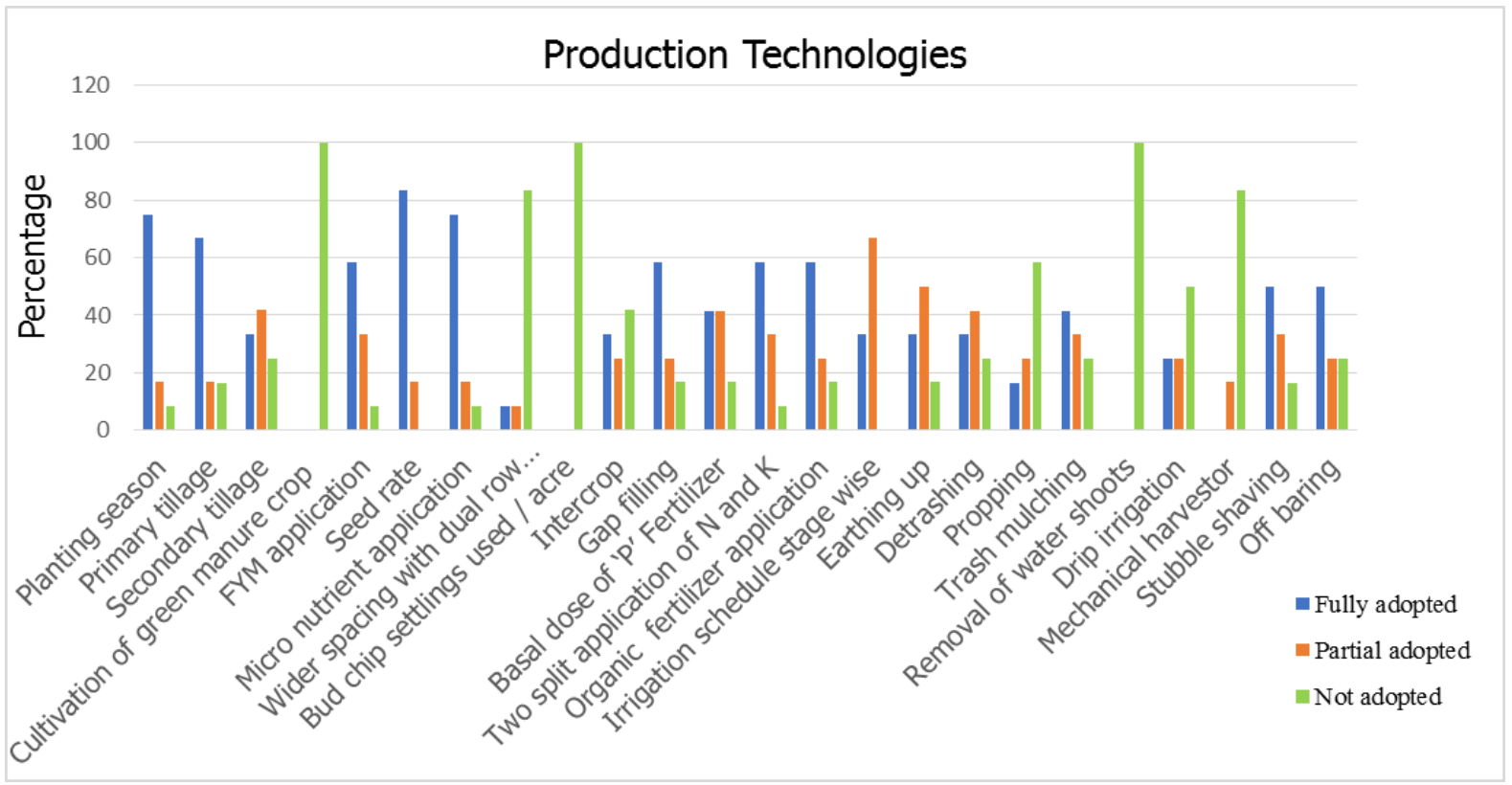

Fig. 1. Sugarcane Production and protection technological dimensions in Theni district of Tamil Nadu state.

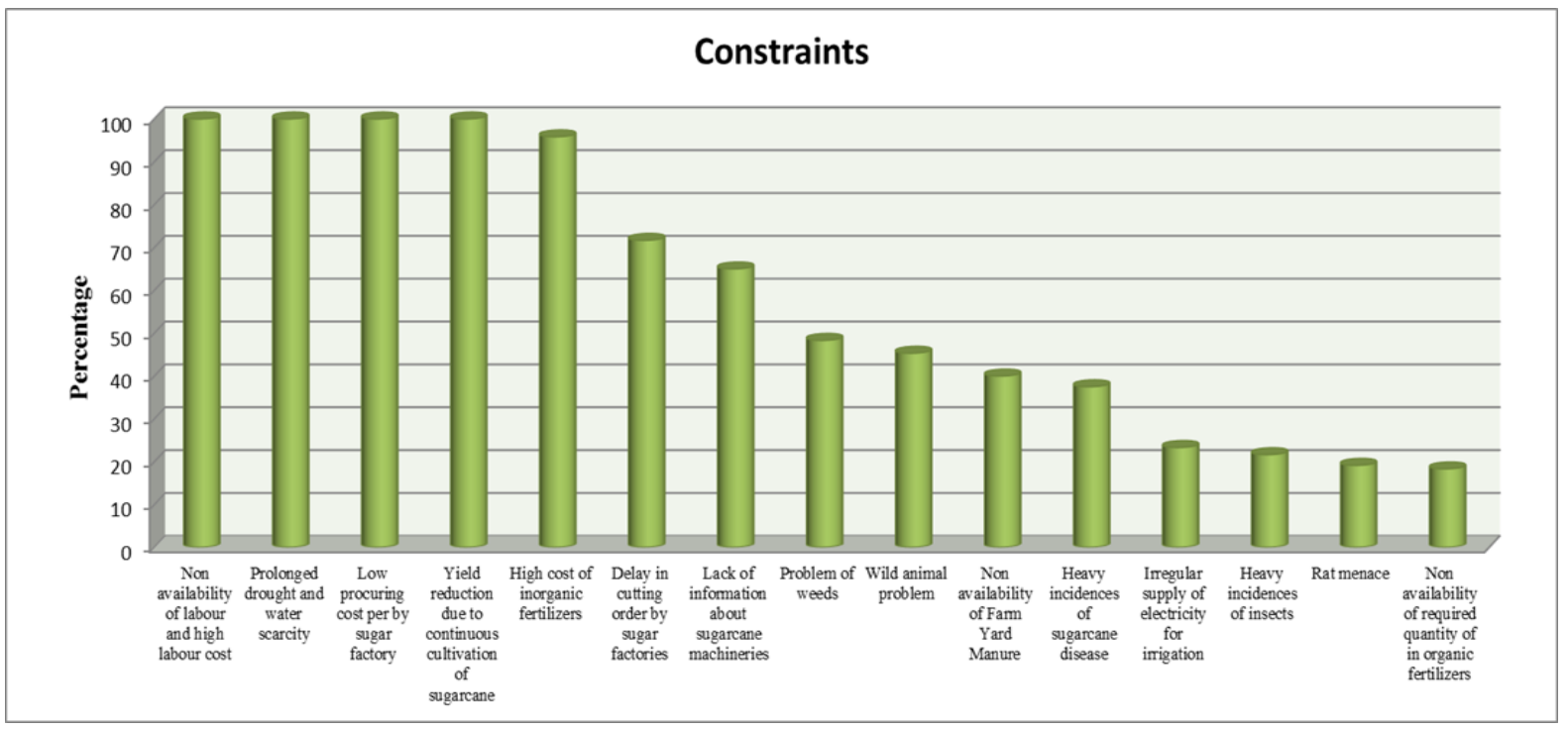

Fig. 2. Constraints encountered by sugarcane farmers in Theni district of Tamil Nadu state.

ing TOT strategy for water management in canal command area of lower Bhavani project. Study on risk orientation revealed that medium to high level of risk orientation was observed more among sugarcane farmers $(83.4 \%)$. It is quite natural that as a cash crop; sugarcane needs higher investment, obviously the farmers who are ready to take up risk; those farmers only will go for cane cultivation. The results were in agreement with Karpagam (2007) who observed that the majority of grape growers $(75 \%)$ had medium level of risk orientation.

Technological dimension: In the present study various technologies were studied in three-point continuum and respondents were classified into three categories viz., complete adoption, partial adoption and not adoption categories. It can be observed from Table 2 that the technologies, seed rate $(83.3 \%)$, planting season $(75.00)$, primary tillage with mould board / disc plough (67\%), gap filling, two split application of $\mathrm{N}$ and $\mathrm{K}$ application $(58.3 \%)$, stubble shaving, off baring $(50.0 \%)$ had adoption rate of more than 50 percentage. Since the above said technologies are the pre- requisite in sugarcane cultivation and had higher adoption by the cane growers. In case of ratoon crop; stubble shaving and off-barring are the inevitable, therefore the adoption rate also in higher trend 
Table. 3. Constraints encountered by Sugarcane farmers in Theni district of Tamil Nadu state $(n=60)$.

\begin{tabular}{|c|c|c|c|c|}
\hline S.N & Problems & $\begin{array}{l}\text { Total } \\
\text { score }\end{array}$ & $\begin{array}{l}\text { Mean } \\
\text { score }\end{array}$ & Rank \\
\hline 1. & Non-availability of labour and high labour cost & 6000 & 100 & $\mathrm{I}$ \\
\hline 2. & Prolonged drought and water scarcity & 6000 & 100 & II \\
\hline 3. & Low procuring cost by sugar factory & 6000 & 100 & III \\
\hline 4. & Yield reduction due to continuous cultivation of sugarcane & 6000 & 100 & IV \\
\hline 5. & High cost of inorganic fertilizers & 5750 & 95.83 & $\mathrm{~V}$ \\
\hline 6. & Delay in cutting order by sugar factories & 4300 & 71.67 & $\mathrm{VI}$ \\
\hline 7. & Lack of information about sugarcane machineries & 3900 & 65 & VII \\
\hline 8. & Problem of weeds & 2900 & 48.33 & VIII \\
\hline 9. & Wild animal problem & 2750 & 45.33 & IX \\
\hline 10. & Non availability of Farm Yard Manure & 2400 & 40.00 & $\mathrm{X}$ \\
\hline 11 & Heavy incidences of sugarcane disease & 2250 & 37.50 & $\mathrm{XI}$ \\
\hline 12 & Irregular supply of electricity for irrigation & 1400 & 23.33 & XII \\
\hline 13. & Heavy incidences of insects & 1300 & 21.66 & XIII \\
\hline 14. & Rat menace & 1150 & 19.16 & XIV \\
\hline 15. & Non availability of required quantity of in organic fertilizers & 1100 & 18.33 & $\mathrm{XV}$ \\
\hline
\end{tabular}

(Fig. 1). These findings are in line with the findings of Sriram and Palaniswamy (2000) who found that ploughing season, hand weeding and synchronized planting were adopted by cent per cent of the respondents in cotton cultivation. In case of fertilizer application majority $(58.3 \%)$ of the farmers fully adopted the practice. This may be due to that the high level of knowledge by the farmers about fertilizer application. This finding was supported by the findings of Qudsiya et al. (2016) who reported that 93.54 per cent of the sugarcane farmers had knowledge about applying fertilizer through fertigation.

The technologies, basal dose of ' $P$ ' fertilizer $(41.6 \%)$, trash mulching $(41.6 \%)$, secondary tillage $(33.3 \%)$, intercrop (33.3\%), irrigation scheduling $(33.4 \%)$ and drip irrigation (25\%) had less than $50 \%$ per cent of adoption rate. These are all the technologies which are optional. The adoption rate for these technologies mostly depends upon the money and labour availability with the farmers. Hence, the technologies had lesser adoption. In case of intercultural operation the practices viz., earthling up and de-trashingwas not adopted by the very meager per cent of the respondents viz., 16.7 and 25 per cent respectively. These findings are in confirmation with the findings of Deepika et al. (2018) who reported that inter cultivation practice i.e. hand weeding was not adopted by very meager percentage (1.50) cotton growers. Technologies Viz., cultivation of green manure crop, bud chip settling, removal of water shoots had no adoption by the respondents. Normally farmers are not removing water shoots because of its added advantage for more weightage. The similar findings were reported by Selvam (2014) as very low adoption pattern (less than 20 per cent) was observed for intercrop, propping, removal of water shoots and mechanical harvester while studying the technology mapping for sugarcane technologies in Dharmapuri district.

Constraint analysis: A set of constraints were identified during the pre-test survey and the same were listed out and presented to the respondents during the main survey. The identified problems were administered to the respondents and asked them to give their ranks in the order of merit. To evolve at meaningful conclusions, Garrett's ranking technique was used and the computed results are furnished in Table 3.

Table 3 indicated that the major constraints faced by cent per cent of the respondents were; non availability of labour and high labour cost, prolonged drought and water scarcity, low procuring cost per by sugar factory, yield reduction due to continuous cultivation of sugarcane. Nonavailability of labour and high cost of labour is the major problem not only in the study area but also in other parts of Tamil Nadu. Last few years Tamil Nadu faces the severe drought and majority of the farmers shifting to other crop cultivation instead of sugarcane. Suresh (2014) reported while studying the constraints analysis in sugarcane production system in Perambalur district that prolonged drought and water scarcity $(97.50 \%)$, irregular electricity supply $(93.33 \%)$, non-availability of labour and high cost of labour (89\%), high cost of in -organic fertilizer $(81.6 \%)$ and low procuring cost by sugar factory $(80.00 \%)$ were the major problems reported by the sugarcane farmers. Other constraints viz., problem of weeds $(48.33 \%)$, wild animal problem (45.33\%), non-availability of FYM $(40.00 \%)$, heavy incidence of disease $(37.50 \%)$, irregular supply of electricity $(23.33 \%)$, heavy incidence of insects $(21.66 \%)$, rat menace $(19.16 \%)$, non-availability of in-organic fertilizer (18.33\%) 
were scored less than 50 score in the study area (Fig.2).

\section{Conclusion}

The investigation on this research issue was a maiden attempt to explore the status of sugarcane cultivation in Theni district in three different dimensions viz., social, technological and constraints. It clearly explored the present status of adoption level by the farmers for the production and protection technologies of sugarcane. The study on social dimensions opened up different avenues for extension workers to understand the socioeconomic status of the sugarcane farmers in the Theni district. Adoption of agricultural technologies is a very crucial factor. Hence the present study address the adoption level of various cane production and production technologies which will support the researchers and extension workers to re-orient their technology transfer strategies for better adoption level of cane technologies. In the changing scenario of agriculture; non-availability of labour and high labour cost are the major constraints in any crop cultivation. The present study identified the major constraints involved in the sugarcane cultivation. If the constraints are seriously viewed by different stake holders and the efforts if taken to minimize those constraints then it will lead to the dream of sustainable cane cultivation in Tamil Nadu.

\section{REFERENCES}

1. Balasubramaniam, P. (2005). Developing TOT strategy for water management in canal command area of lower Bhavani project. Ph.D., Thesis, TNAU, Coimbatore.

2. Deepika, M., Asokhan, M and Usha Rani, S. (2018). Adoption behavior of ELS cotton growers in Vellore district of Tamil Nadu. Journal of Extension Education, 30(1).

3. Karpagam, C. (2000). A study on the Knowledge and Adoption Behaviour of Turmeric Growers in Erode district of Tamil Nadu State. M.Sc. (Ag.) Thesis,

\section{UAS, Dharwad.}

4. Karpagam, C. (2007). Farmers' Interest Group in grape production - an impact analysis. Ph.D. Topical Research Report, TNAU, Coimbatore.

5. Karpagam, C. (2009). Socio technological analysis of drip irrigation. Unpub. Ph. D Thesis, TNAU, Coimbatore.Karpagam, C., PuthiraPrathap, D and Moovendhan, P. (2016). Farmer let gross root level entrepreneurial initiatives for sustainable sugarcane production system in Tamil Nadu, India. Journal of Applied and Natural Science, 8(4).

6. Karpagam, C., PuthiraPrathap, D and Moovendhan, P. (2016). Farmer let gross root level entrepreneurial initiatives for sustainable sugarcane production system in Tamil Nadu, India. Journal of Applied and Natural Science, 8(4): 2249-2255

7. Kumaran, M., Sundaram, M., Shijo Mathew and Anand PR. (2018). Socio-personal contour, information flow and productivity of brackishwater aquaculture systems - an appraisal. Journal of Extension Education. 30(3): 6119-6128

8. Mooventhan, P., Kadian, K.S., Senthilkumar, R and Karpagam, C. (2015). Socio-econmoc profiling of tribal dairy farmers in Northern hills zone of Chhattisgarh. Journal of Extension Education. 27(3): 55175523.

9. Ramasubramanian, $T$ and Karpagam, C. (2014) FAQs on early shoot borer, Kissan world, 41(9):19-21

10.Selvam, M.K. (2014. A study on technology mapping fpr sugarcane technologies in Subramaniya siva cooperative sugar mill area of Dharmapuri district. M.Sc. ODL Thesis, TNAU, Coimbatore.

11.Sunitha Varghese. (1998). Knowledge and Adoption of Eco-friendly Farm Technologies in Paddy. M.Sc. (Ag.) Thesis, TNAU, Madurai.

12.Suresh, G. (2014). A study on constraint analysis in sugarcane production system in Perambalur sugar mills LTD (TASCO), Perambalur district. M.Sc. ODL Thesis, TNAU, Coimbatore.

13.Sriram, N and Palaniswamy, A. (2000). Cotton growers' extent of awareness about the eco- friendly agricultural practices in cotton. Journal of Extension Education. 11(2).

14.Qudsiya Jamal, K., Shanthasheela, M and Vasanthapriya. (2016). Knowledge level of sugarcane growers on sustainable sugarcane initiative. Journal of Extension Education, 28(2). 